\title{
EFFECTIVE WRITING ASSIGNMENTS FOR TECHNICAL COURSES
}

\author{
R. Moore, J. V. Strueber \\ Tuskegee University
}

\section{Introduction}

This paper is the result of the authors' work incorporating writing assignments into the technical courses that they teach without increasing the professor's workload and detracting from the coverage of the course topics. The writing assignments described herein are designed to address the communications skills needed by practicing professionals and contribute to the student's understanding of the topic at hand. One of the authors first presented the process at an ACSA Technology Conference in 1992; ${ }^{1}$ since then the assignment has been further developed, expanded, enhanced, and refined.

Professionals must be able to write daily reports to document progress on the job or project activities, to evaluate, and to summarize the work of others. They must be able to compose clear, succinct technical reports on a regular basis; they also need to be able to speak in front of groups of people, ranging from directing workers in the office, to the instructing at the jobsite, to making formal public presentations. This means being able to write and speak clearly and concisely and to present the material so it can be clearly understood by the intended audience. Professionals also need to review a seemingly endless number of trade and professional publications to keep abreast of their field.

Our students are expected to summarize information quickly and clearly on examinations, write technical laboratory reports, and produce papers that are more formal. The writing courses included in most college curriculums help build basic communication skills; however, research confirms that continuous practice is required to improve these skills, to build students' confidence, and to tie the skills to practice. Research on learning also suggests that writing can be used to enhance and support learning.

The process described in this paper provides the student continuous experience in acquiring these skills in somewhat painless--and maybe even in an enjoyable-process while introducing them to the breadth and depth of their chosen field. In addition, the assignments have been structured so as not to require grading in order to be effective. 


\section{The Theory--Learning and Teaching Styles}

Allan A Gatthorn in Curriculum Renewal suggests that writing can be used as a method of learning. "The idea of using writing as a method of learning is grounded in sound theory, as Yinger and Clark ${ }^{2}$ have noted in Reflecting Journal Writing: Theory and Practice. "Writing is integrative, entailing the active use of one's total intellectual equipment; writing requires symbolic manipulation, which in turn facilitates learning; writing serves as an epistemic function, modifying the human knowledge it records; writing in (is?_doesn't make sense otherwise) a unique mode of learning involving all the major types of learning; writing provides both immediate and long-term self-provided feedback; writing is active and personal; and writing is a self-paced mode of learning." 3 There seems to be a consensus among educational researchers that a person retains information best when the learner has to actively deal with the material. This active participation can be achieved through immediate practice, such as in problem sets, by explaining or summarizing the material, or through test taking.

Robert S. Zais, in Curriculum: Principles and Foundations, ${ }^{4}$ holds that educator should first determine the purpose of the education and then create a curriculum and method of teaching to produce that result. It is important to keep this concept in mind when developing writing assignments. Writing assignments tied to course goals and professional skills are well received by the students. If the assignments are too informal or too broadly defined, the students may develop the attitude that the assignment is just something to keep them busy.

\section{The Need}

Professionals must keep abreast of new developments in their fields to be successful. The available body of literature is quite large and this process can be time consuming and tedious. An effective method is to quickly scan the current literature, selecting specific material in the area of interest for further review. In school, students are accustomed to having material provided by the textbook and reinforced by the lecture and assignments. Students tend to limit their intellectual interests to material covered in class. It can take new graduates years to develop effective methods of staying abreast of new developments in their fields.

This assignment is adapted from the way communication theory was taught in a seminar taken by one of the authors took while a graduate student. In that class, the instructor assigned a series of articles for the students to find and read. Each student wrote an abstract of each paper following a given format and distributed it to the other students in the class. The seminar format was to have each student lead the discussion on his or her paper.

The abstract assignment described in this paper was developed to acquaint students with sources of current knowledge in their field and to encourage them to develop the habit of continually scanning the current literature in their areas of interest. In this assignment, the students write a series of short "abstracts" 
of technical papers or presentations and share them with the class. Another quite-effective version is used in a building economics class where the students scan the current events to determine if any event or issue may affect the practice of their profession.

The original goals for the assignment were to:

- expand the range of material that is possible to cover in the limited class time and to expose students to the diversity of their profession;

- allow the freedom to explore a particular item of interest to greater depth;

- give students a chance to contribute to the class and provide experience in evaluating the work of others;

- save the professor's time by using students to expand and update the professor's abstract reference file; and

- minimize any increase in grading time.

As technical professionals we often are required to communicate throughout our day though written memos and reports as well as orally. This can range from simple file notes of phone conversations, meetings, and inspections or daily reports of job site activates to various meetings and presentations with clients, agencies, and other professionals. With graduates commenting that the "abstract assignment" gave them skills that assisted in gaining in early promotions - due to their better communication skills - it became apparent that the abstract assignment also was assisting the student to learn other important professional skills. Because of this feedback, additional goals in developing communication skills were added to the abstract assignment to assist in further developing and enhancing the learning of these important professional communication skills. These are to develop methods that:

- enhance oral communications skills and

- show the student how this format can be easily adapted to the style needed for the various reports and record-keeping on the job.

\section{The abstract}

Originally, the assignment given was to review a professional journal article of the students' choice and to write and distribute copies of the abstract to the class. The students were given a "generic" structured format and examples to follow (see Figure 1). The review at a minimum included a description of the main topic of the paper, a summary of the results, and a personal evaluation of the quality or appropriateness of the article, looking at whether the work contributed to the general knowledge of the field and whether the class should consider reading it.

General guidelines were: the abstract was limited to one page in length, it was word processed, and the articles and papers were to be selected from an approved list of journals with exceptions to be preapproved. No more than one article could be selected from one issue and no more than two from any one 
journal; in addition, any one article could be reviewed only once in the term-if someone else had reviewed the article, it could not be reviewed again. The article was to be properly referenced. The students were to give a copy to the professor and one to each class member. One abstract was due each week and exams included questions from the abstracts. Usually, the students had full freedom to choose whatever articles they wished provided the articles were related to the content of the class, however, at times selected areas were assigned to enhance the class work. If a student discovered a particularly relevant article, the class might be directed to read the article as a class assignment.

Students were told that while the professor values good writing and correct grammar and spelling, they would not be graded on these items. The abstracts were graded only on content with two possible grades possible--“acceptable or unacceptable"--with a hastily done haft-hearted effort being unacceptable. Because of the process followed, this resulted in better papers than when they were graded by the professor.

To enhance learning professional communication skills, which the former students reported to be a useful outcome of the assignment, we expanded the assignment to include oral presentation of the abstracts. The number of abstracts actually presented was dependent on available class time and, when appropriate, the student led the class in a discussion on the subject. The purpose of this addition was to enhance the learning through practice in public speaking in a controlled and more-comfortable environment. This exercise by no means takes away from the importance of including specialized technical writing and speaking classes in the program; it does, however, reinforce the skills learned in the writing classes while at the same time expanding the technical course content and learning.

A variation of the abstract assignment includes an analysis of how current events or issues may affect the students' chosen profession. In this variation - in a class in the economics of development and building-the students review news articles on current issues or events that may affect the economics of architecture, development, or the construction industry and report back to class the issue or event and its relevance, including its possible effects. Sources are the local and national newspapers, the internet, $P B S$, the Economist, Time, Newsweek, or other appropriate sources. The "abstract" follows a similar format to the journal review with the exception that the section titled "Summary of Results/Conclusions of the Article" is removed and more space is devoted to the personal evaluation. In this particular case, the oral presentation is critical to the subject-learning process as it allows the professor to direct a class discussion on the particular issue.

Based on the feedback reports from former students, the handouts given to the students and classroom discussions have been changed to show how the assignment format is the same as the project file entry for reporting various project events such as phone conversations, field inspections, and various meetings from project team to client meetings. Comments from graduates about the usefulness of the skills learned from the assignment in earning early promotions are included to enhance the acceptance of the assignment. 


\section{The Results}

In addition to exposing the students to current literature, the assignment also assists in developing the habit of remaining current in their fields. For most students it significantly improves the ability to quickly summarize and report. And, most important, writing skills improve as do their grades in classes that require reports and or essay-style answers in tests. (Perhaps technical students tend to write poorly because of lack of practice in their areas of interest.) Since including the oral presentations, the authors have seen an improvement in the willingness and ability of the students to enter into class discussions and to ask appropriate questions.

Students often scan and read portions of several articles selecting the "best" one to review. Those students seeking an "easy" article to review are typically exposed to more material than those who simply get to it, with the result that they gain more from the assignment in their attempt to make it easier.

Initially students were required to distribute ungraded copies of their abstracts to the other class members to increase the breath of exposure to the literature and to save time. At first, a paper copy was distributed; now the internet is used for the distribution. In general, the students do not like distributing their work to other class members. Resistance is lessened by explaining that as "professionals" they will be required to distribute written material not only to coworkers, but also to clients. This has been described as "nearly as bad as giving an oral report." However, there are several real benefits: the grammar, spelling, and sentence structure, the general writing skills, and the overall quality of the abstracts tends to improve consistently with each assignment, even without being graded. The general quality is much higher than when the professor grades assignments. The students seem to be far more sensitive to the opinions of their peers than to the professor's comments. To encourage this, everyone is required to read all the abstracts and questions from the abstracts are included in exams.

The oral component of the abstract helps to enhance verbal capabilities in a controlled setting - often people are terrified to speak in front of groups. By having the students present their abstracts informally to the class, they get to practice verbal skills in a comfortable environment with less fear of failure. Usually it works well if the instructor can evaluate and give suggestions to students about their presentation in the established conversational tone of the seminar. On occasion, a more private personal evaluation is appropriate.

At first, students tend to have difficulty evaluating the articles or events they choose. They may not have an adequate basis on which to judge the quality or appropriateness of the article. However, requiring them to express a critical opinion of others' work reinforces the idea that technical publications must be read critically and not accepted at face value. 
The students report that they are gaining from this assignment. In discussion, students frequently revealto themselves--what they actually learned that doing the abstracts. There seems to be a sense of achievement in contributing important material to the class-especially in discovering things that are new to the professor. Students gain insight into how current consensus practice evolves and how new knowledge is integrated into practice. Former students relate that they still scan the journals. Some students have changed the direction of their careers because of what they have learned in reading the journals as a continuation of doing this simple assignment. We are convinced that for a technical professional, the skills honed in this assignment are invaluable tools for success in this growing global world. 
REQUIRED FORMAT FOR THE ABSTRACTS. ABSTRACTS MUST BE WORD-PROCESSED AND FOLLOW THIS FORMAT INCLUDING THE SPACE ALLOWED FOR EACH OF THE TOPIC AREAS.

Abstract: ARCH 534

REVIEWER/DATE: (Your name and date due)

TITLE/AUTHOR/SOURCE/DATE OF THE ARTICLE OR EVENT REVIEWED: (Give full academic reference)

SUMMARY: (Description of the main topic of the article or event)

SUMMARY OF THE RESULTS/CONCLUSIONS OF THE ARTICLE: (if an event add this space to the personal evaluation below):

PERSONAL EVALUATION OF HOW THE ARTICLE OR EVENT AFFECTS THE PRACTICE OF ARCHITECTURE, DEVELOPMENT OR BUILDING CONSTRUCTION:

Figure 1, Sample Abstract Format

Proceedings of the 2004 American Society for Engineering Education Annual Conference \& Exposition

Copyright (C) 2004, American Society for Engineering Education 
1 Strueber, J. V. and Nelson, D. C., Writing Assignments in Architectural Courses that Enhance Teaching Effectiveness, Making Environments: Technology and Design, the Association of Collegiate Schools of Architecture, (1992). This paper is an update of that paper showing the developments in the assignment since publication.

2 Yinger, R. J. and Clark, C. M., Reflecting Journal Writing: Theory and Practice, Institute for Research on Teaching, Michigan State University (1981)

3 Allan A Glatthorn, Curriculum Renewal, Association for Supervision and Curriculum Development, 68, (1987)

$4 \quad$ Zais, Robert S., Curriculum: Principles and Foundations, Thomas Y. Crowell, Inc. (1976)

\section{R. MOORE}

Instructor, Department of Architecture/Construction Program, Tuskegee University, She received her BS in Construction Science from Tuskegee, prior to joining the construction faculty in the spring of 2003 she was an estimator in the construction industry in Chicago.

JAMES V. STRUEBER, Architect

Associate Professor, Dept of Architecture/Construction Program, Tuskegee University, He has maintained a international consulting practice specializing in architectural design, construction and management. Primary focus has been in the area of housing, residential design, project, and construction management. Work has included international institutional strengthening, management consulting, national housing policies and implementation plans. 